\title{
An empirical investigation into the relationship between sustainability and supply chain compliance within the South African Public and the private sector
}

\author{
Faith Mashele \\ Tinashe Chuchu \\ University of the Witwatersrand, South Africa
}

\section{Keywords}

Compliance; Supply Chain; Leadership; Sustainability, Procurement

\begin{abstract}
The objectives of the study were to comprehend the influence of regulatory compliance on the adoption of sustainable procurement practices by organisations, whilst examining whether decision makers in supply chains have the capacity to balance compliance and the interests of various stakeholders in supply chain management decision making processes. This research submits that supply chains play a significant role in ensuring that the contribution towards sustainability goals is enhanced, using the lens of stakeholder theory, institutional theory and the PESTEL framework. The approach adopted for the present research involved descriptive statistics and hypotheses tests that were utilised to quantitatively investigate primary research data that was collected using a survey involving 247 supply chain and sustainability practitioners within the public and the private sector. It was observed that practitioners are able to incorporate and translate stakeholder considerations into compliant requirements. Finally, the results demonstrated that there is a significant relationship between regulatory compliance and sustainability, highlighting the contribution of supply chain compliance towards driving sustainable development. The implications for academicians, researchers and practitioners were identified, in which new approaches to existing concepts were established. This research contributes to contemporary knowledge on sustainable procurement and supply chain management. Additionally, the empirical findings concluded that regulatory compliance has a direct influence on the acceptance of sustainable procurement by organisations particularly through internal policies that are tailored to emulate the business environment and culture.
\end{abstract}

Corresponding author: Tinashe Chuchu

Email addresses for corresponding author: tinashechuchu4@gmail.com

First submission received: 3 rd May 2017

Revised submission received: 12th July 2017

Accepted: 10th August 2017

\section{Introduction}

Sustainability has evolved into a business mega-trend that influences the expectations placed on business culture and governance in various fundamental ways, thus imploring a new type of leadership within organizations (Tideman, Arts \& Zandee, 2013). It is therefore incumbent on the private and the public spheres to serve as enablers for business in order to increase the influence of sustainable development through responsible leaders and responsible business globally (Tavishvili, 2015). The private and the public sector have a role to play in adopting responsible sourcing and engaging in sustainable procurement approaches. Griggs (2013) suggests that a shift in the economic landscape is imperative in order to achieve sustainable and significant impact for societies. Stank and Autry (2011) postulate that the supply chain arena is a key business function and an imperative driver for financial performance as the function has direct cost implications on the bottom line and improved customer service. For Mashele (2016), the benefit that is sought in the long run across the board revolves around advancing considerations that have a long-term impact on the social, environmental and economic facets of the society. Sustainability, therefore, carries an opportunity for business to adopt strategies that will align their contribution with the global sustainable development goals that are set by the United Nations (Wiggins, 2015). 


\section{Problem Statement}

Pagell and Shevchenko (2014) assert that sustainability in supply chains is a topical research area that has moved from the periphery to mainstream research in the past two decades. Furthermore, research suggests that while much progress has been done to address social and environmental issues, the question of how to create truly sustainable supply chains remains unanswered (Metcalf \& Benn, 2013; Cuthbertson, 2011; Meehan \& Bryde, 2011). It is purported that there are various facets that encompass societal concerns that affect sustainability strategies which are influenced by factors external to the organisation (Touboulic, Chicksand, \& Walker, 2014). To that end, power dynamics of various stakeholders come into play in shaping the organisation's response to societal issues that emanate from stakeholder pressure. For this reason, this research study set out to investigate the influence of stakeholder pressure that emanates from the regulatory environment for procurement and supply chain management in South Africa and the associated impact on achieving sustainable development objectives.

This paper is therefore presented as follows: The first section outlines the theoretical grounding for the research study constructs, followed by the development of the conceptual framework. The research design methodology, results and findings are provided in the subsequent section. Lastly, the conclusion and the recommendations of the study are presented.

\section{Literature review}

Creswell (2014) posited that literature serves as a roadmap for ongoing dialogue around an area of research while assessing and results of prior studies. Furthermore, literature acts as a conduit to introduce hypothesized relationships in a particular research study. This section explores the theoretical adopted for the present study.

\section{Stakeholder Theory}

Freeman (2011) argued that stakeholder theory revolves around management of the different interest groups and their interconnectedness in the process of creating value for organisations. The role and responsibility of leaders towards their organisations and stakeholders was elevated by the global economic crisis (Doh\& Quigley, 2014). Furthermore, Doh and Quigley (2014) explored the relationship between stakeholder theory and responsible leadership where they suggested that responsible leaders should leverage expertise and organisational intelligence in order to influence organisational outcomes. Similarly, Mashele (2016) advanced that responsible leaders are able to direct outcomes of the organisation through their interconnected networks and various interactions within the organisation. Despite this, stakeholders have diverse values and needs, and thus, due to limited resources, there will be a disposition to select the most suitable alternative which prioritises the interests of the organisation within a decision-making process (Pagell \& Shevchenko, 2014). In view of this, Pagell and Shevchenko (2014) recommended that future research was required to explain how managers make responsible decisions in a complex and adaptive supply chain system.

Meehan and Bryde (2011) highlighted that the role of supply chains in driving forward the corporate sustainability agenda is critical, given its position and its ability to influence the external environment through the procurement function. The concept of sustainability in business is often located within the context of corporate social responsibility which is concerned with the role of business and the inherent responsibility that business has towards diverse stakeholders. According to Christensen, Mackey and Whetten (2014) sustainability as a philosophy is centered on the extent of the influence of organisations. This influence is a collective effort that is shaped by actions of individuals that lead, support and drive sustainability strategy and initiatives that contribute to wider long-term benefits. It was therefore important in this research study to understand the influence of the individual behaviours relating to the adoption of sustainability within organisations particularly within a supply chain context. Consequently, prior research has shown that it is critical to understand the macroeconomic context which governs the landscape upon which sustainable practices are implemented (Ferri, Oelze, Habisch \& Molteni, 2014; Yüksel, 2012; Meehan \& Bryde, 2011). Carbone, Moatti and Wood (2012) highlighted the role of stakeholder pressures as a contributing and guiding factor in the adoption of sustainability practices within the organisations. Notwithstanding this, Hoejmose and Adrien-Kirby (2012) recommended that future research should aim to contextualise the influence of political and government 
factors that inform the regulatory universe of business and organisational policies. By the same token, Ferri, et al (2014) suggested that future research should aim to highlight the influence of local regulations on decision making processes relating to sustainable procurement.

\section{Institutional Theory}

Institutional theory suggests that business practices and organisational behaviour are influenced by institutional structures that are affected by political, social, economic and cultural forces (Nurunnabi, 2015). Equally, private organisations are renowned for operating in a domain and a context that is different from the public sector and thus would be generally be subject to differing regulatory requirements. Though this is the case, research suggests that the business decisions for advancing inclusive procurement conform to institutional structures that embody organisational values and appeal to various stakeholders (Theodorakopoulos, Ram, \& Kakabadse, 2015).Vracheva and Mason (2015) argued that institutional theory aims to explain the inherent regulatory, social and cultural factors in various industries thatimpose inflexibility on how organisations strategically respond to external pressures.Consequently, organisations will be inclined to behave and act in a socially responsible manner within a context where regulatory compliance is enforceable (Vracheva \& Mason, 2015). On the contrary, Yüksel (2012) suggested that macro-economic contexts may have a direct influence on the ideologies that are adopted by organisations and encouraged that it is necessary to recognise the connection and the interdependence that may exist considering that political context might have economic, social, environmental and legal implications.

\section{Regulatory Compliance}

According to Brammer and Walker (2011), supply chain management represents an important policy tool that could help to achieve outcomes that are consistent with broader societal policy goals. By the same token, Ambe and Badenhorst-Weiss (2012) argued that, the public supply chain management process in South Africa is supported by the provisions of the Constitution of the Republic of South Africa in order to address past inequitable policies and practices. In order to ensure that this objective is achieved, a point system for awarding preference within government supply chain management processes was introduced by the National Treasury as a means to achieve socio-economic objectives (Ambe \& Badenhorst-Weiss, 2012). Silvestre (2015) in his study observed the implementation of sustainable supply chain management in emerging economies and found that the ecosystem within which organisations operate shapes and affects the acceptance of sustainability objectives within its business practices. On the other hand, Adam et al. (2012) posited that the focus on strict compliance to regulatory requirements contributes to the administrative burden and complexity within decision making processes for procurement. In addition, they held that managers who are involved in both the public and private procurement domain are often subjected to constraints within the decision-making processes. In view of this, Adam et al. (2012) recommended that future research should seek to assess how an amicable balance is achieved to promote efficient process and ethical behaviour by managers operating in these environments.

\section{The PESTEL Framework}

It has been suggested that the PESTEL framework, as shown below, may be used to understand the drivers that influence sustainability practices within organisations. The framework demonstrates that it is imperative to consider the context within which the organisation is situated in order to understand the influences by political, economic, social, technological, environmental and legal factors that may affect the organisation (Yüksel, 2012). To that end, it is asserted that sustainability encompasses various aspects of this framework which are positioned to focus on regulatory compliance with a view to address socioeconomic as well as environmental objectives. 


\section{Figure 1: The PESTEL Framework}

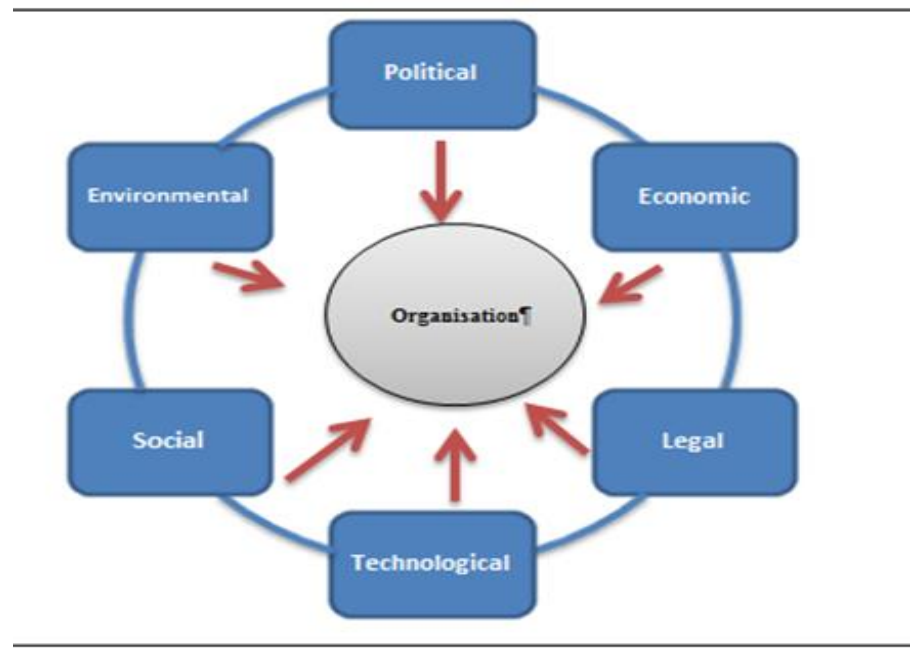

(Source: Yüksel, 2012, p.57)

Figure 1 above presents the PESTEL (Political, Economic, Social, Technological, Environmental and Legal) framework which was adopted for this study. For Phakathi (2015), inclusive growth in an economy is a mechanism that will intensify the impact of sustainability and encourage shared hope and development of communities. Conversely, stringent rules are an obstacle to economic development and for progressive contribution that will shrink the widening gap of inequality globally (Phakathi, 2015). According to Turley and Perera (2014), the governing legislation in South Africa, provides opportunities forpromoting social priorities that provide sufficient space to pursue environmental sustainability and economic development objectives. Jeffery (2013), however, on the contrary, argued that the regulatory prescripts that are intended to advance socio-economic goals in South Africa are too rigid to allow for inclusive participation and serve as a barrier to development and sustainability.

\section{Research Methodology}

The study adopted a positivist approach which was quantitative in nature. The software used for analysis was the Statistical Analysis Software (SAS ®) and survey administration was conducted using Survey Monkey ${ }^{\mathrm{TM}}$. The decision to use Survey Monkey ${ }^{\mathrm{TM}}$ was made as it was deemed an appropriate tool to access respondents that where geographically dispersed more effectively and more efficiently. Descriptive statistics were conducted on that research data in-order to make logical inferences from that data. Furthermore, model fit checks and as well as hypotheses tests were conducted.

\section{Population and Unit of Analysis}

The area of study focused on respondents working in the Gauteng province of South Africa where research data was collected from collected from 247 supply chain and sustainability managers within the public and the private sector.

\section{Sampling Method and Sample Size}

The researchers used a combination of purposive and expert sampling which are non-probability sampling methods. Purposive sampling was considered appropriate for this research study as it allowed for the selection of cases that would answer the research questions in relation to the objectives of the study (Bryman \& Bell, 2011).

\section{The Research Instrument}

According to Maziriri (2016) a questionnaire is defined as any set of specific questions for obtaining information from the participants in order to meet the objectives of the study. A 5-point Likert scale questionnaire was developed for this research study. The rating scale was based on 1- 5, where 1 was "strongly disagree" and 5 was "strongly agree". According to Kumar (2014) using a Likert scale to collect data is valuable as it indicates the strength of competing views on a subject. The author posited that a questionnaire is a convenient and economical form of collecting data from a large population; however, 
the limitations of a questionnaire include the fact that information cannot be improved by further questioning or observations from respondents.

The questionnaire consisted of 51 questions spread across five subsections; Section A, B, C, D \& F. Section A was demographics of the respondents. Section B consisted of statements around the opinions of the respondents regarding the level of adoption of sustainable practices by their respective organisations. Bryman and Bell (2011) posited that the use of existing questions from previous research studies may be considered in the questionnaire design, either with the intention of replication or as input into designing questions for the research study. The author suggested that the inclusion of pre-existing research questions may be convenient as the questions have already been pre-tested.

The research questions in this research study were largely based on the literature reviewed; where in Section C, D and F, the questions were linked to the literature themes for this research study. The questionnaire consisted of questions which were informed by previous research studies and were adapted for this study as shown in Table 1.

\section{Table 1 Research Questions Adapted from Previous Studies}

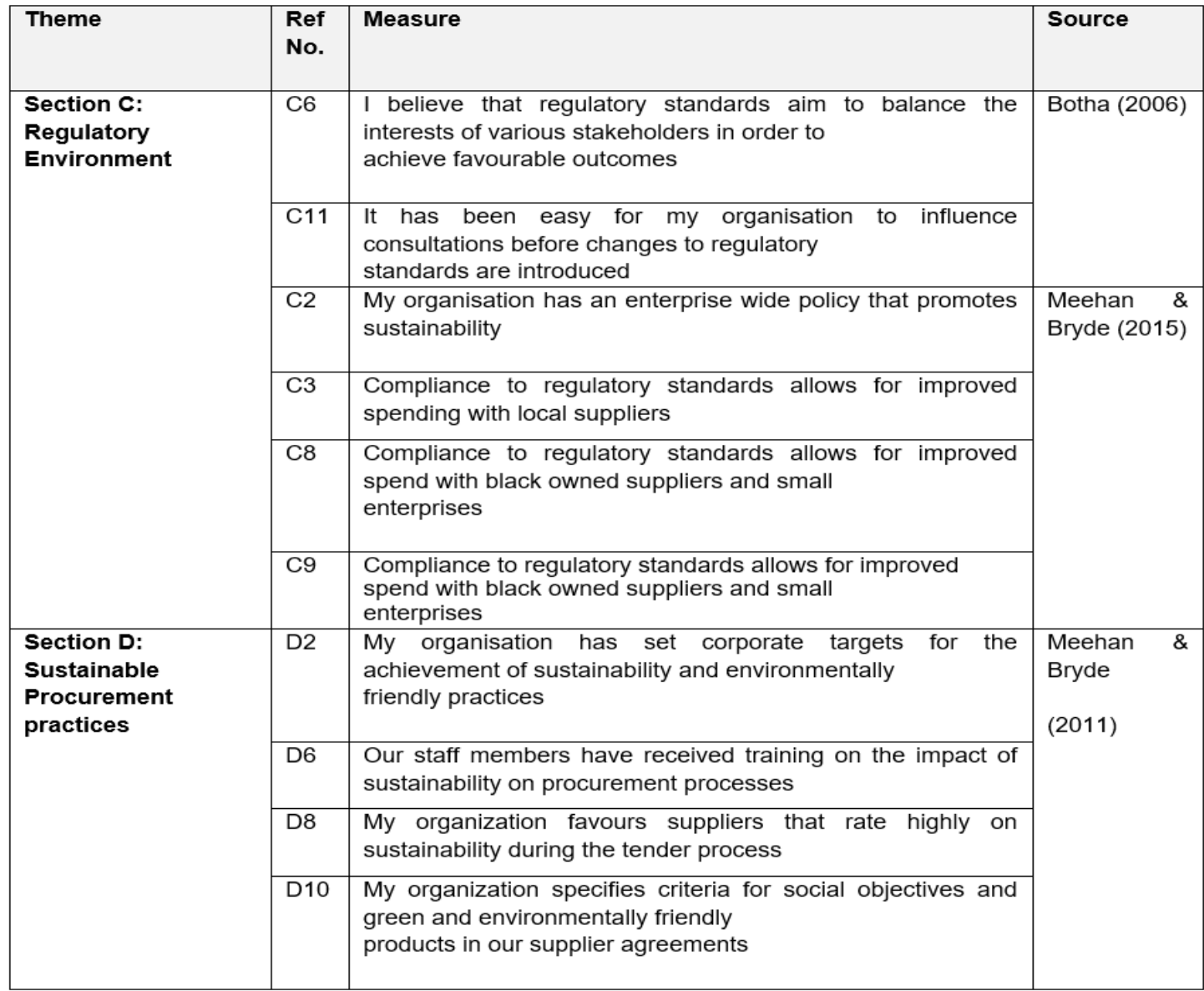

\section{Results of the study}

Descriptive Statistics

A total number of 247 respondents participated in the survey that was administered via Survey Monkey ${ }^{\mathrm{TM}}$. The breakdown of the demographics of respondents in the sections that follow: 


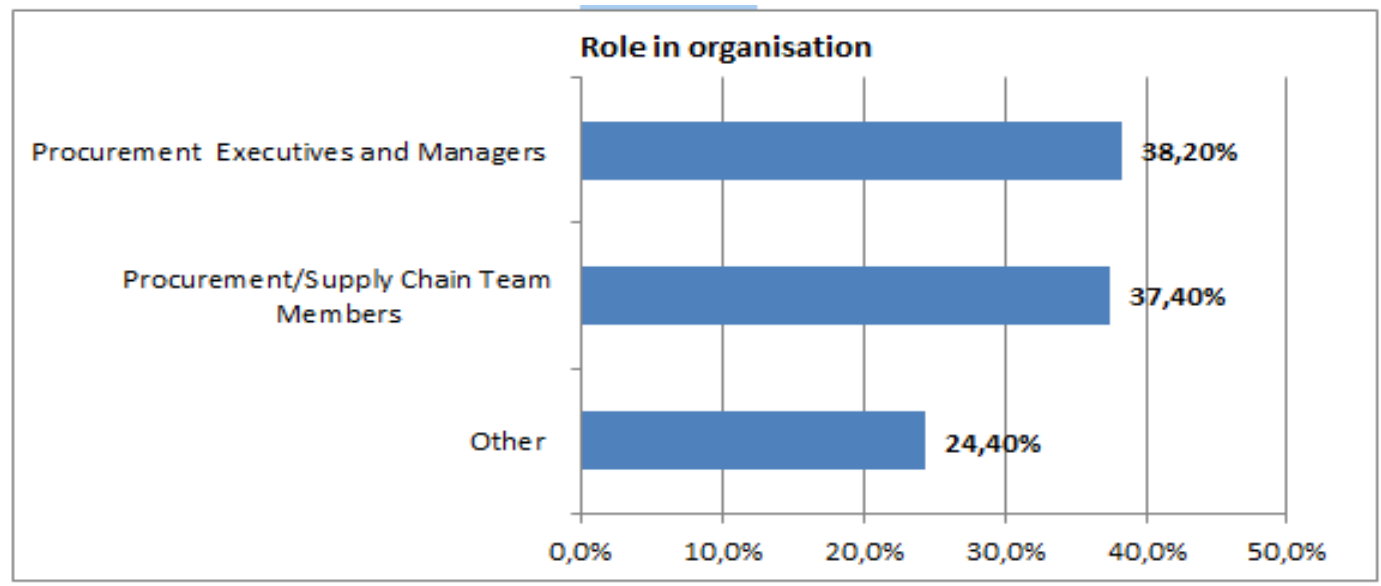

Figure 2: Role in Organisation

The results in figure 2 above indicated that the majority of the respondents were at executive director and procurement and supply chain manager level at 39\%. More than a third of the respondents $(37 \%)$ were practitioners that are involved in various supply chain and procurement project teams with $24 \%$ of the respondents were classified as "other" which is a provision that the researchers used to accommodate the difference in terminology and designations that are adopted within various organisations.

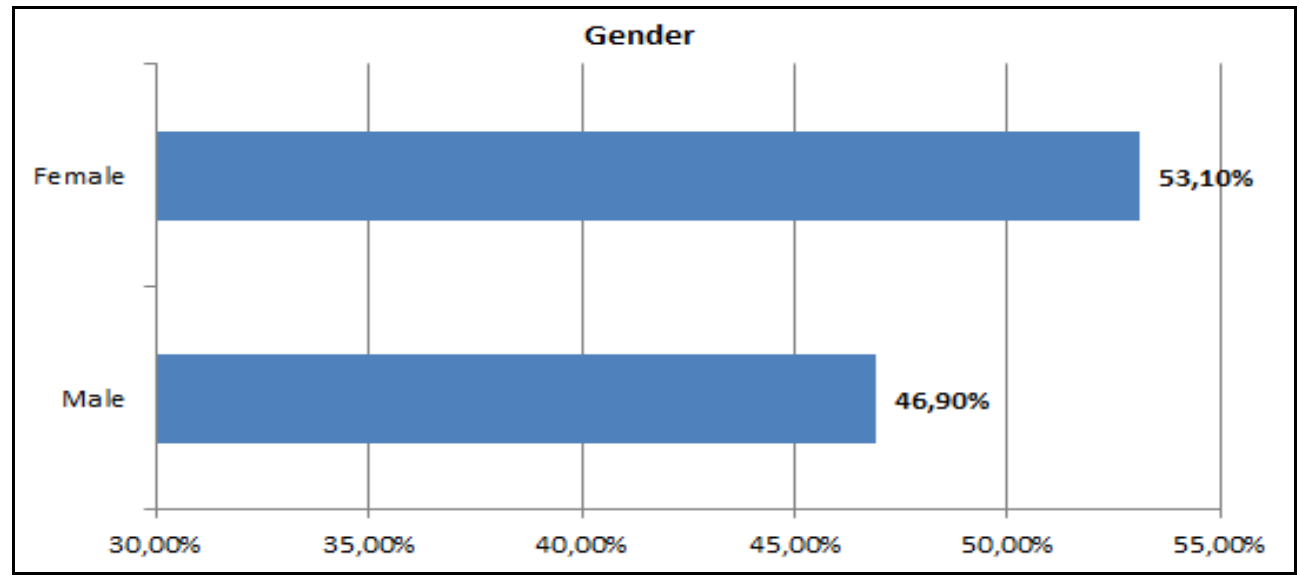

Figure 3: Sample distribution by Gender

Figure 3 above shows the respondents according to gender. The results indicate that there was a majority proportion (53\%) of female respondents that participated in the research survey compared to males at $47 \%$.

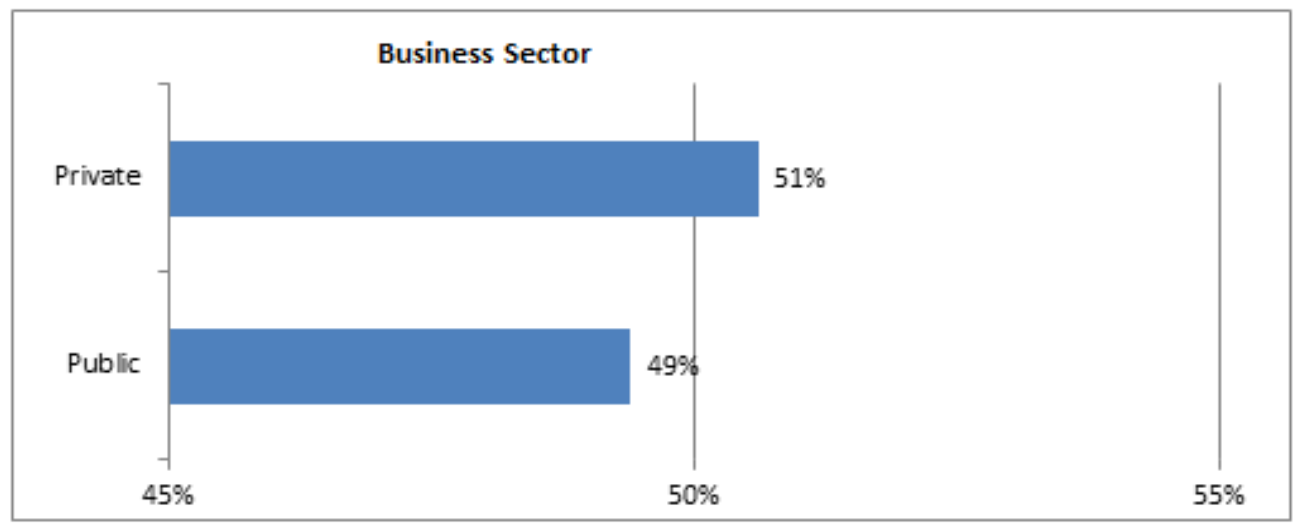

Figure 4: Sample distribution by Business Sector 
Figure 4 depicts the distribution of the respondents according to business sector. The results indicate that there was an almost equal spread in terms of business sector with the majority of the respondents being employed within the private sector at $51 \%$ and a slight variance being employed within the public sector at $49 \%$.

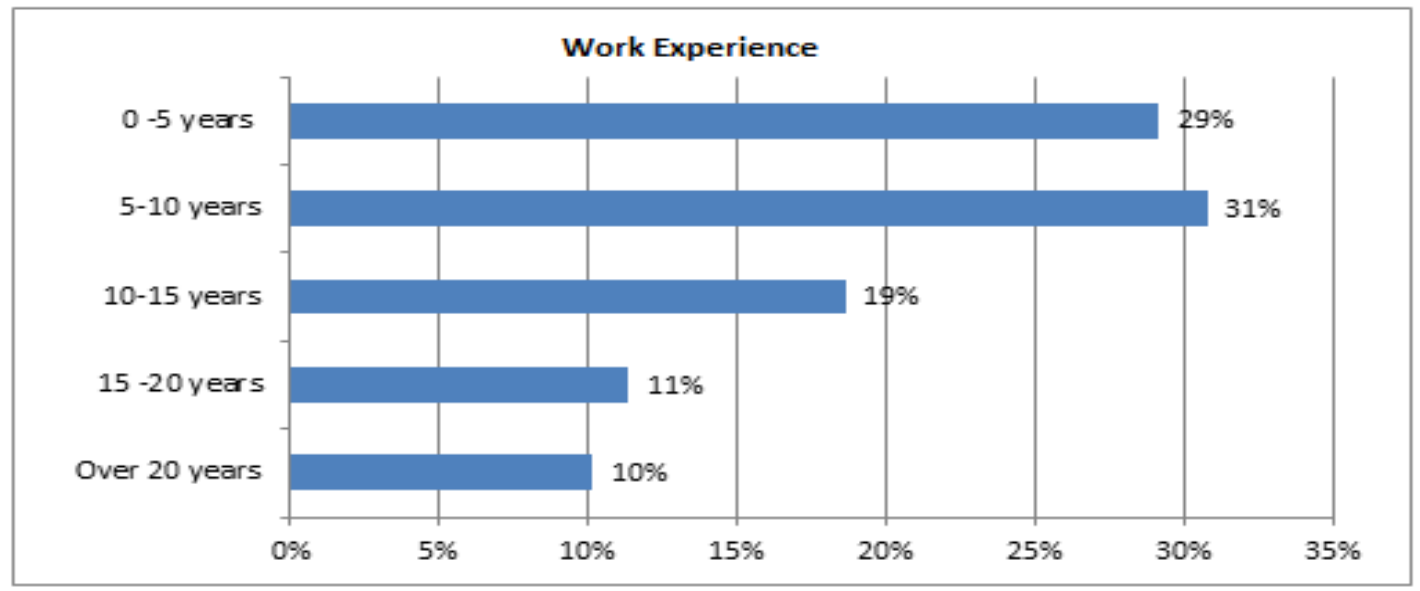

Figure 5: Sample distribution by Work Experience

Figure 5 indicates that $29 \%$ of the respondents had less than 5 years of work experience while the majority accounting for almost a third of the respondents (31\%) have between 5 and 10 years work experience. Of the 247 respondents that participated in the survey, it was observed that a third of the respondents have more 10 years work experience with $10 \%$ being a seasoned and mature calibre of practitioners with over 20 years work experience within the area of procurement and supply chain management.

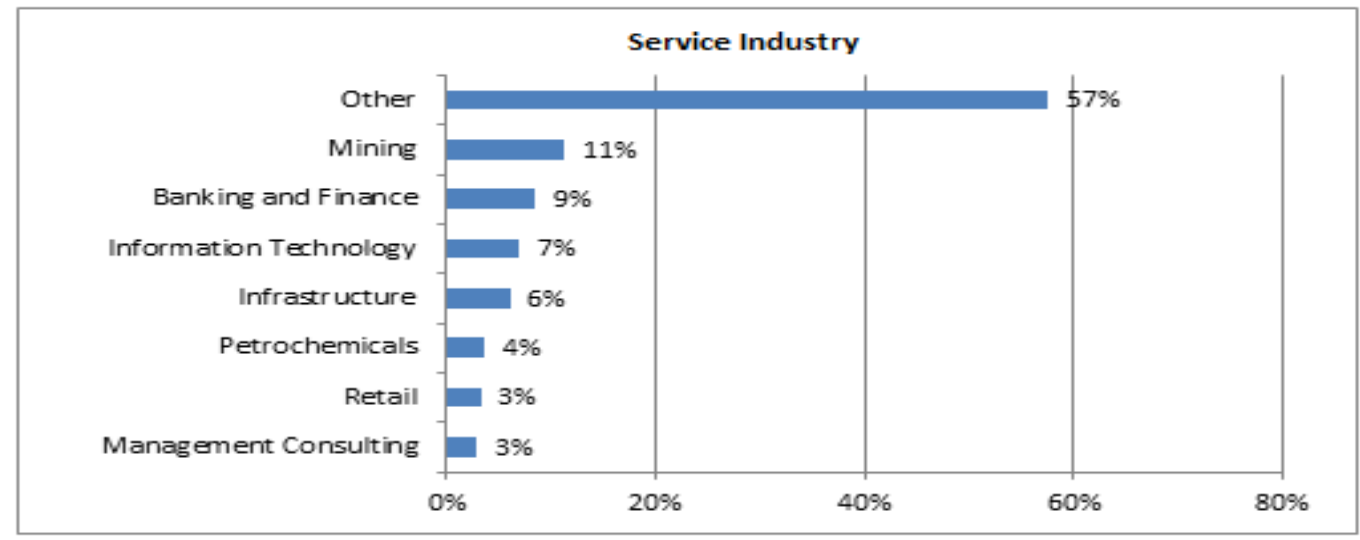

Figure 6: Sample distribution by Service Industry

Figure 6 presented the distribution of the respondents according to service industry. The results show that the respondents are employed across various service industries with the majority of the respondents at $57 \%$. The results depict that over a tenth of the respondents $(11 \%)$ were within the mining industry while $9 \%$ were employed within the banking and finance industry. Further to this, the figure indicates that $7 \%, 6 \%$ and $4 \%$ were employed respectively within the information technology, infrastructure and petrochemical industries. The least number of the respondents $(3 \%)$ were from retail and management consulting services.

\section{Research Question}

Does supply chain compliance influence the adoption of sustainable procurement by organisations?

Research question was intended to test empirically whether supply chain compliance, in the absence of other influencing factors, has an influence on sustainability within supply chain management processes. 
The hypothesized association is indicated in Figure 7 where regulatory compliance was the dependent variable and sustainability was the independent variable. The results of the basic path analysis that was carried out to test the relationship between the two variables is presented in Table 2.

The goodness of fit test is indicated in Table 3.

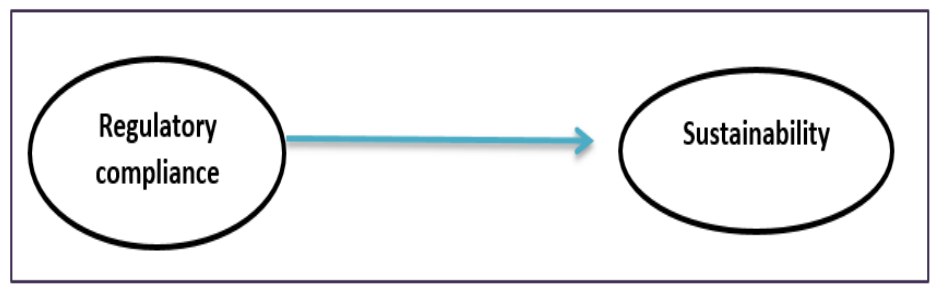

Figure 7: Relationship between regulatory compliance and sustainability

It was found that regulatory compliance indeed influenced the adoption of sustainability within supply chain management processes by organisations as supported by the other findings of the study.

\section{Research Hypothesis}

The researchers formulated a hypothesis that was tested at a 95\% confidence level.

Research has suggested that regulatory compliance, particularly in a procurement context, generally differs across the business sectors and various industries (Nurunnabi, 2015; Theodorakopoulos, Ram, \& Kakabadse, 2015). It was therefore important to understand the impact of regulatory compliance on sustainability, within the public and the private sector. To this end, while both the public and the private sector are guided by internal policies, it was assumed that a highly regulated environment would be subject to both internal and external regulation. The hypothesized association is depicted in Figure 8.

The hypothesis was set out as follows:

Null Hypothesis (1): H0: $\rho=0$, There is no association between a highly regulated procurement environment and the successful adoption of sustainable procurement

Alternative Hypothesis (1): H1: $\rho>0$, There is an association between a highly regulated procurement environment and the adoption of sustainable procurement.

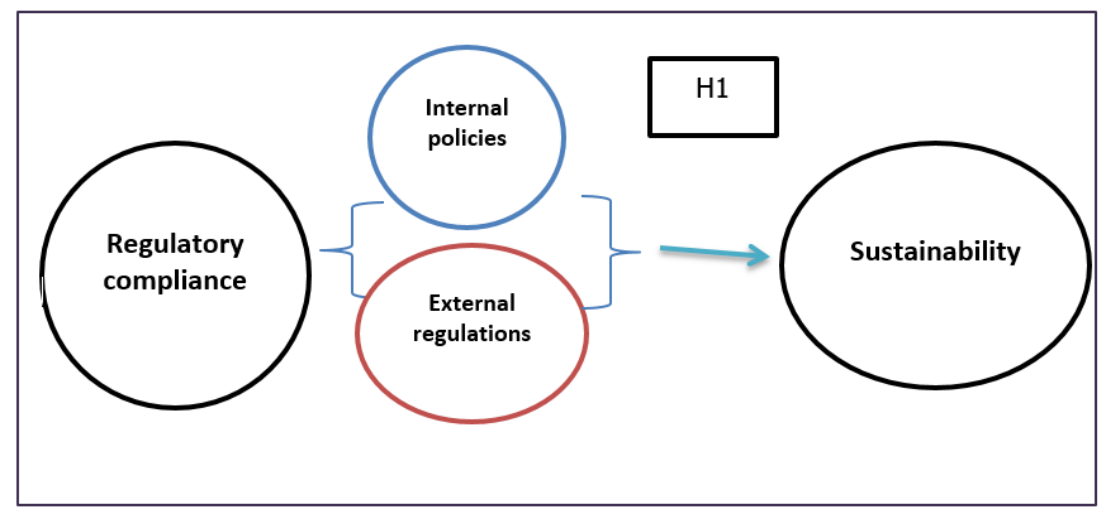

Figure 8: Research Hypothesis: Internal Policy, External Regulation and Sustainability association

Figure 8 indicates the association where internal policy and external regulations are the dependent variables and the sustainability is the independent variable. The results of the test that was run are shown in Table 2 and the outcome of the goodness of fit test is indicated in Table 3. 


\begin{tabular}{|c|c|c|c|c|c|c|c|c|}
\hline \multicolumn{9}{|c|}{$\begin{array}{c}\text { The CALIS Procedure } \\
\text { Covariance Structure Analysis: Maximum Likelihood Estimation }\end{array}$} \\
\hline \multicolumn{9}{|c|}{ PATH List } \\
\hline \multicolumn{4}{|l|}{ Path } & \multicolumn{2}{|c|}{ Parameter } & Estimate & $\begin{array}{l}\text { Standard } \\
\text { Error }\end{array}$ & t value \\
\hline $\begin{array}{l}\text { Internal } \\
\text { Policy }\end{array}$ & $\Rightarrow=\Rightarrow$ & \multicolumn{2}{|c|}{ Sustainability } & \multicolumn{2}{|c|}{ _Parm1 } & 0.49287 & 0.04878 & 10.10343 \\
\hline $\begin{array}{l}\text { External } \\
\text { Regulations }\end{array}$ & $\Rightarrow=\Rightarrow$ & \multicolumn{2}{|c|}{ Sustainability } & \multicolumn{2}{|c|}{-Parm2 } & 0.24146 & 0.06592 & 3.66290 \\
\hline \multicolumn{9}{|c|}{ Variance Parameters } \\
\hline $\begin{array}{l}\text { Variable } \\
\text { Type }\end{array}$ & \multicolumn{2}{|l|}{ Variable } & \multicolumn{3}{|c|}{ Parameter } & Estimate & $\begin{array}{l}\text { Standard } \\
\text { Error }\end{array}$ & t value \\
\hline Dependent & \multicolumn{2}{|c|}{$\begin{array}{l}\text { External } \\
\text { Regulations }\end{array}$} & \multicolumn{2}{|c|}{ Add1 } & & 0.38715 & 0.03743 & 10.34408 \\
\hline Independent & \multicolumn{2}{|c|}{ Internal Policy } & \multicolumn{2}{|l|}{-Add2 } & & 0.70696 & 0.06834 & 10.34408 \\
\hline Independent & \multicolumn{2}{|c|}{ Sustainability } & \multicolumn{2}{|c|}{-Add3 } & & 0.21714 & 0.02099 & 10.34408 \\
\hline \multicolumn{9}{|c|}{ Covariances Among Independent Variables } \\
\hline Var1 & \multicolumn{2}{|l|}{ Var2 } & \multicolumn{3}{|c|}{ Parameter } & Estimate & $\begin{array}{l}\text { Standard } \\
\text { Error }\end{array}$ & t Value \\
\hline $\begin{array}{l}\text { Internal } \\
\text { Policy }\end{array}$ & \multicolumn{2}{|c|}{$\begin{array}{l}\text { External } \\
\text { Regulations }\end{array}$} & \multicolumn{2}{|c|}{-Add4 } & \multicolumn{2}{|c|}{0.32959} & 0.04227 & 7.79758 \\
\hline \multicolumn{9}{|c|}{ Squared Multiple Correlations } \\
\hline \multicolumn{2}{|l|}{ Variable } & \multicolumn{3}{|c|}{ Error Variance } & \multicolumn{2}{|c|}{ Total Variance } & \multicolumn{2}{|l|}{ R-Square } \\
\hline \multicolumn{2}{|l|}{ Sustainability } & \multicolumn{3}{|c|}{0.21714} & \multicolumn{2}{|c|}{0.48990} & \multicolumn{2}{|r|}{0.5568} \\
\hline
\end{tabular}

Table 2: Covariance Structure Analysis

Based on the results in Table 2, it can be concluded at a 95\% confidence that a significant relationship exists between both internal policy criteria and that a significant relationship also exists between external regulations as the t-values are above 1.96. It is interesting to note that internal regulations variable has a higher value (10.10) when compared to external regulations (3.66). The $r-$ squared value is 0.55 which indicates a strong relationship between the variables as the number tends towards 1.

\begin{tabular}{|c|c|c|}
\hline \multicolumn{3}{|c|}{ Fit Summary } \\
\hline & Number of Observations & 215 \\
\hline \multirow{8}{*}{ Modelling info } & Number of Variables & 3 \\
\hline & \begin{tabular}{|l|} 
Number of Moments \\
\end{tabular} & 6 \\
\hline & \begin{tabular}{|l|} 
Number of Parameters \\
\end{tabular} & 6 \\
\hline & \begin{tabular}{|l} 
Number of Active \\
Constraints
\end{tabular} & 0 \\
\hline & \begin{tabular}{|l|} 
Baseline Model Function \\
Value
\end{tabular} & 1.3193 \\
\hline & \begin{tabular}{|l} 
Baseline Model Chi-Square \\
\end{tabular} & 282.3317 \\
\hline & $\begin{array}{l}\text { Baseline Model Chi-Square } \\
\text { DF }\end{array}$ & 3 \\
\hline & $\begin{array}{l}\text { Pr > Baseline Model Chi- } \\
\text { Square }\end{array}$ & $<.0001$ \\
\hline \multirow{6}{*}{ Absolute Index } & Fit Function & 0.0000 \\
\hline & \begin{tabular}{|l} 
Chi-Square \\
\end{tabular} & 0.0000 \\
\hline & \begin{tabular}{|l} 
Chi-Square DF \\
\end{tabular} & 0 \\
\hline & $\begin{array}{l}\text { Root Mean Square Residual } \\
\text { (RMR) }\end{array}$ & 0.0000 \\
\hline & \begin{tabular}{|l} 
Standardized RMR (SRMR) \\
\end{tabular} & 0.0000 \\
\hline & \begin{tabular}{|l} 
Goodness of Fit Index (GFI) \\
\end{tabular} & 1.000 \\
\hline
\end{tabular}

Table 3: Model Fit Summary 
The p-value for the structural model as shown in Table 3 is less than 0.0001 which is lower than 0.05. This signifies that the hypothesized association between the two variables is confirmed and suggests that there is a significant relationship between regulatory compliance and sustainability is significant. The goodness of fit index for the model is 1 which shows that a good fit between the data and the model.

\section{Contributions to research}

It is believed that this research study contributed to existing literature as follows:

Firstly, it contributed to existing research study around the adoption of sustainable supply chain management. Secondly, the empirical research that was conducted has confirmed that supply chain compliance influences the adoption of sustainable supply chain management by organisations while adding to the existing body of knowledge by indicating that internal policies have a higher influence on the adoption of sustainable supply chain management. This new insight implies that internal policies can drive better sustainable supply chain management practices as they are adapted to resonate with the business environment and culture.

\section{Limitations of Research}

The following limitations should be noted:

- The impact of sustainable procurement on the overall performance of organisations was beyond the scope of this study

- The research sample may not be representative of the entire population as purposive sampling was used for this study. It is noted that membership to the procurement professional body which the majority of the respondents were affiliated to, is not compulsory for procurement and supply chain management practitioners in South Africa

- The research study does not look at the impact of supplier relationships on sustainable procurement

- The leadership lens does not extend to leader-follower relationships which may be an element that influences the adoption of sustainable development

\section{Managerial implications}

\section{Recommendations for regulators}

The findings of this study have shown that regulatory compliance contributes to business decisions that ultimately contribute towards advancement of social, economic and environmental considerations. In view of this, regulators should endeavour to create an enabling regulatory environment through progressive prescripts that guide inclusive development by business and government.

\section{Recommendations for organisations}

To reiterate, the private and the public sector have a role to play in advancing social, economic and environmental considerations through the day-to-day business activities. The procurement function cuts across various business requirements that are key to the functioning of the organisation. For this reason, organisations should realise that beyond the compliance lens that is often used to look at the role of procurement lies a key proposition to deliver and enhance the impact on development outcomes.

\section{Recommendations for managers}

The findings of this research have suggested that managers consider processes that involve adopting sustainable procurement practices. To this end, it is recommended that organisations should aim towards implementing and driving internal policies that consider compliance whilst offering flexible models for advancing sustainability objectives.

Last, but not least, this research study has highlighted the important role that is played by leaders in the adoption of sustainable procurement within the organisation. It therefore is encouraged for managers in their interactions with various stakeholders should aim to interpret sustainability objectives to users and translate it back in a manner that is cognisant of compliance requirements.

\section{Recommendations for academicians}

Lastly, recommendations for academicians were established. Academicians stand to benefit from the literature review that was conducted for purposes of this study as well as an enhanced comprehension 
of the PESTEL framework, stakeholder theory and institutional theory within the context of supply chain management.

\section{Conclusions}

The present study was an empirical investigation into the relationship between sustainability and supply chain compliance within the South African public and private sector. It was established that there is an association between a highly regulated procurement environment and the adoption of sustainable procurement. Further research could, extend the present study by incorporating the impact of collaboration and supplier relationships on sustainable procurement. Lastly, future researchers could consider utilising different research frameworks as to those of this study so as to observe if the same results could be replicated.

\section{References}

Adam, F., Csaki, C., Prier, E., \& Bufacchi, V. (2012). Ethical decision making and decision support systems in public procurement - A theoretical discussion. Supply Chain Forum: an International Journal, 13(3), 70-81.

Ambe, I., \& Badenhorst-Weiss, J. (2012). Procurement challenges in the south african public sector. Journal of Transport and Supply Chain Management, 6(1), 242-261. doi:10.4102/jtscm.v6i1.63

Brammer, S., \& Walker, H. (2011). Sustainable procurement in the public sector: an international comparative study. International Journal of Operations EProduction Management, 31(4), 452 - 476.

Bryman, A., \& Bell, E. (2011). Business research methods. Oxford: Oxford University Press.

Carbone, V., Moatti, V., \& Wood, C. H. (2012). Diffusion of sustainable supply chain management: Toward a conceptual framework. In Supply Chain Forum: An International Journal 13,(4,) 26-39

Christensen, L. J., Mackey, A., \& Whetten, D. (2014). Taking responsibility for corporate social responsibility: the role of leaders in creating, implementing, sustaining or avoiding socially responsible firm behaviors. The Academy of Management Perspectives, 28(2), 164-178.

Creswell, J. W. (2014). Research design: Qualitative, quantitative, and mixed methods approaches. Los Angeles: Sage Publications.

Cuthbertson, R. (2011). The Need for Sustainable Supply Chain Management. In B. Cetinkaya, R. Cuthbertson, G. Ewer, T. Klaas-Wissing, W. Piotrowicz, \& C. Tyssen, Sustainable supply chain management: practical ideas for moving towards best practice (pp. 3-13). Heidelberg Dordrecht London New York: Springer Science \& Business Media. doi:10.1007/978-3-642-12023-7

Doh, J. P., \& Quigley, N. (2014). Responsible leadership and stakeholder management: Influence pathways and organizational outcomes. The Academy of Management Perspectives, 28(3), 255-274.

Ferri, L. M., Oelze, N., Habisch, A., \& Molteni, M. (2014). Implementation of responsible procurement management: An Institutional Perspective. Business Strategy and the Environment. doi:10.1002/bse.1870

Freeman, R. E. (2011). Managing for stakeholders: Trade-offs or value creation. Journal of Business Ethics, 96, 935. doi:10.1007/s10551-011-0935-5

Griggs, D. (2013). Sustainable development goals for people and planet. Nature's International Weekly Journal of Science, 495, 305-307.

Hoejmose, S. U., Roehrich, J. K., \& Grosvold, J. (2014). Is doing more doing better? The relationship between responsible supply chain management and corporate reputation. Industrial Marketing Management, 43, 77-90.

Jeffery, A. (2010). Chasing the rainbow: South Africa's move from Mandela to Zuma. South African Institute of Race Relations.

Mashele, F. (2016). The Relationship Between Sustainability and Compliance in a Procurement Context. MBA Thesis, Gordon Institute of Business Science, University of Pretoria.

Maziriri, E. T. (2016). The influence of perceived social risk and buying behaviour on

apparel store choice decision among generation Y female students within the Sedibeng district. Master's dissertation. Vaal University of Technology. Vanderbijlpark.

Meehan, J., \& Bryde, D. (2011). Sustainable Procurement Practice. Business Strategy and the Environment, 20, 94-106. 
Metcalf, L., \& Benn, S. (2013). Leadership for sustainability: An evolution of leadership ability. Journal of Business Ethics, 112, 369-384. doi:10.1007/s10551-012-1278-6

Nurunnabi, M. (2015). Tensions between politico-institutional accounting regulation in a developing economy: insights from institutional theory. Business Ethics: A European Review, 24(4), 398 - 424.

Pagell, M., \& Shevchenko, A. (2014). Why research in sustainable supply chain management should have no future. Journal of Supply Chain Management, 50(1), 44-55.

Phakathi, B. (2015, June 29). Without real inclusivity, there can be no growth. Retrieved from Business Day: http:/ / www.bdlive.co.za

Silvestre, B. M. (2015). A hard nut to crack! Implementing supply chain sustainability in an emerging economy. Journal of Cleaner Production, 96, 171-181.

Stank, T. P., \& Autry, P. W. (2011). The new supply chain agenda: a synopsis and directions for future research. International Journal of Physical Distribution \& Logistics Management, 40(10), 940 - 955. doi:10.1108/09600031111185220

Tavishvili, T. (2015, June 25). Global compact companies send clear message in un general assembly. Retrieved from The Financial: http:/ / finchannel.com/

Theodorakopoulos, N., Ram, M., \& Kakabadse, N. (2015). Procedural Justice in Procurement Management and Inclusive Interorganizational Relations: An Institutional Perspective. British Journal of Management, 26, 37-254. doi:10.1111/1467-8551.12071

Tideman, S. G., Arts, M. C., \& Zandee, D. P. (2014). Sustainable leadership towards a workable definition. Journal of Corporate Citizenship, 49, 17-33.

Touboulic, A., Chicksand, D., \& Walker, H. (2014). Managing Imbalanced Supply Chain Relationships for Sustainability: A Power Relationships for Sustainability: A Power. Decision Sciences, 45(4), 577 - 619.

Turley, L., \& Perera, O. (2014). Implementing sustainable public procurement in south africa: Where to start. The International Institute for Sustainable Development.

Vracheva, V., \& Mason, R. (2015). Creating Firm Value through Stakeholder Management and Regulation. Journal of Managerial Issues, XXVII(1- 4), 120-140.

Wiggins, K. (2015, June 2). UN sets sights on sustainable development goals. Retrieved from The Financial Times: http://www.ft.com

Yüksel, İ. (2012). Developing a Multi-Criteria Decision Making Model for PESTEL Analysis. International Journal of Business and Management, 7(24), 52-66. 